DOUBLE TORSION TESTING*

EVALUATION FOR ASTM E-24.07.02

by

J.-C. Pollet and S.J. Burns

Department of Mechanical \& Aerospace Sciences

and

The Materials Science Program

University of Rochester

Rochester, NY 14627

\title{
Introductory comments
}

Our equipment for double torsion testing had been specifically designed for testing large and long polymer (e.g. PMMA) double torsion samples. Consequently:

(a) Only two samples could be cut from each 6 " $\times 6^{\prime \prime}$ plate in order to fit our equipment. The sample length was only about twice its width.

(b) The compliance and relaxation in the machine and loading fixture was too large for performing the present test under optimum conditions. Although this has no effect on the measurement of $\mathrm{K}_{\mathrm{I}}$, a stiff machine/loading fixture relative to specimen stiffness is desirable for more stable precracking, i.e. short precracks. A low-relaxation machine/loading fixture is desirable for using the load relaxation method of determining the crack length.

*This work was supported by U.S. Department of Energy. 


\section{DISCLAIMER}

This report was prepared as an account of work sponsored by an agency of the United States Government. Neither the United States Government nor any agency Thereof, nor any of their employees, makes any warranty, express or implied, or assumes any legal liability or responsibility for the accuracy, completeness, or usefulness of any information, apparatus, product, or process disclosed, or represents that its use would not infringe privately owned rights. Reference herein to any specific commercial product, process, or service by trade name, trademark, manufacturer, or otherwise does not necessarily constitute or imply its endorsement, recommendation, or favoring by the United States Government or any agency thereof. The views and opinions of authors expressed herein do not necessarily state or reflect those of the United States Government or any agency thereof. 


\section{DISCLAIMER}

Portions of this document may be illegible in electronic image products. Images are produced from the best available original document. 
Nevertheless, $K_{\text {IC }}$ data were obtained for pyroceram 9606, and sub-critical crack growth data were obtained for the soda lime glass supplied.

\section{Loading apparatus}

4-point loading device mounted on an INSTRON testing machine, floor model 1115 (see Fig. 1 and Fig. 2).

$W_{M}$, adjustable, was chosen equal to $24.8 \mathrm{~mm}$.

Specimen dimensions and fabrication technique

Pyroceram 9606 and soda lime glass specimens were cut to size with a diamond wheel saw. The V-shape side grooves were also machined with a diamond wheel of the corresponding profile (see Fig. 3). Specimen dimensions are indicated in Table $I$.

\section{Precracking technique and precrack length}

No special machining was done for the purpose of precracking. Instead, a clamp was fixed on the sample in such a way as to (hopefully) prevent the loaded sample from twisting and cracking below that clamp (see Fig: 4). The sample was then progressively loaded in the 4-point loading device (samples A), or loaded in a vice with a 3-point loading arrangement (samples B), until a crack would initiate and jump. The sample was in contact with water during precracking.

The first clamp which was used (on samples A) was not rigid enough and the precrack jumped to a position past the location of the clamp on the sample. Another clamp; more rigid, was used for precracking the samples B. The precrack then jumped to a position before, or about at, the location of the clamp on the sample (see Table II). Precracks on 
samples $B$ were observed to deviate from the bottom of the groove. An : attempt to precrack the other end of glass sample B resulted in the same problem. We now realize that this crack deviation occurred because a small diameter rod was used as the middle loading point and produced a very unsymmetrical loading as the precrack was formed. This probiem: could have been avoided by using a middle loading "point" of a large. contact area to assure relatively symmetrical loading.

After removing the clamp, the sample was placed in the DTT device. and stepwise loaded (crosshead velocity $\dot{\mathrm{X}}=.001 \mathrm{~mm} / \mathrm{s}$ during active. loading). The precrack was allowed to extend via subcritical crack growth while the crosshead was at rest. During this process, the precracks which had previously deviated from the bottom of the groove came back to follow the bottom of the groove.

The precrack lengths at instability for the $K_{I C}$ tests on 9606 glass ceramic were deducted from the observation of the fracture surface of the broken samples and from the known loading histories (Table II).

\section{Testing conditions}

- The tests were performed in distilled water at $21^{\circ} \mathrm{C}$ (room temperature).

- The crosshead velocity, $\dot{x}$, during active loading was $.001 \mathrm{~mm} / \mathrm{s}$.

- The rates of increase in $\mathrm{K}_{\mathrm{I}}, \dot{\mathrm{K}}_{\mathrm{I}}$, during $\mathrm{K}_{\mathrm{IC}}$ testings are indicated on Table III.

- The side groove was on the tensile surface of the specimen.

\section{Crack length measurements}

Crack length is here defined and measured by the distance between 
the loading end of the specimen and the position of the leading edge of the crack on the tensile surface (i.e. the bottom of the groove).

\section{- Glass specimen}

Direct measurement by optical method during subcritical crack growth was easily achieved by using a telemicroscope and proper specimen illumination (Fig. 2). Subcritical crack growth data could therefore be obtained by recording the crack length, and the corresponding load, as a function of time.

\section{- Pyroceram 9606}

It was found extremely difficult to locate the crack tip with our instruments. Polishing the bottom of the groove with 280 grit paper helped seeing better the crack but the magnification of our telemicroscope was not high enough. No direct crack measurement could therefore be obtained. The compliance method for calculating the crack length from load relaxation at constant displacement $\dot{X}$ could not be used either as our machine exhibited too large a relaxation. No subcritical crack growth data could therefore be obtained for this material.

\section{Calculation of stress intensity factor}

$$
\mathrm{K}_{\mathrm{I}}=\mathrm{PW}_{\mathrm{M}}\left[2(1-v) \mathrm{c}_{1} \mathrm{~d}^{3} \mathrm{Wd}_{\mathrm{n}}\right]^{-\frac{1}{2}}
$$

with

$$
c_{1} \simeq \frac{1}{3}-.21\left(\frac{d}{W}\right)+.0175\left(\frac{d}{W}\right)^{5}
$$

and

$$
\begin{aligned}
& v=.22 \text { for soda lime glass } \\
& v=.245 \text { for pyroceram } 9606
\end{aligned}
$$


Experimental results

\section{- Pyroceran 9606}

A total of three. instabilities (defined as a sudden drop in load accompanied by fast crack growth) were observed while loading the samples. They provided three values for ' $\mathrm{K}_{\mathrm{IC}}$ ', equal to each other within 3\% (see Table III). Their average value is:

$$
\mathrm{K}_{\mathrm{IC}}=2.15 \times 10^{6} \mathrm{Nm}^{-3 / 2}
$$

As explained above, no subcritical crack growth data could be obtained, although subcritical crack growth was qualitatively observed to occur.

\section{- Soda lime glass}

Figure 5 shows subcritical crack growth data obtained on Sample B, while the crosshead was stopped at two passive loading positions. Open circles on Fig. 5 are for the first crosshead position $(X=51 \mu \mathrm{m})$ and correspond to a crack growing from a length of $34.5 \mathrm{~mm}$ to a length of $53.9 \mathrm{~mm}$. The crosshead was then moved by another $14 \mu \mathrm{m}$ (new $\mathrm{X}=65 \mu \mathrm{m}$ ) to increase the load on the sample, and again let the crack grow while the crosshead was stopped. The full circles on Fig. 5 correspond then to the crack growing from 57.4 to $88.4 \mathrm{~mm}$.

Since the effective length of the sample is only 1.8 times its width, it would not be surprising that the open circle data at short crack length (i.e. higher velocity region of open circle data) would correspond to overstimated values of $\mathrm{K}_{\mathrm{I}}$ and the full circle data at long crack length (i.e. lower velocity region of full cricle data) would 
correspond to under-estimated values of $\mathrm{K}_{\mathrm{I}}$.

As the crack length was equal to $88.4 \mathrm{~mm}$, the crosshead was moved again at a velocity $\mathrm{X}=.001 \mathrm{~mm} / \mathrm{s}$ in an attempt to reach instability and obtain a $\mathrm{K}_{\mathrm{IC}}$ value. However, as the load increased, the crack velocity increased continuously until the load started to decrease because the crack length was approaching the length of the sample (i.e. in the region of non-linearity between compliance and crack length). No valid. $K_{I C}$ value could therefore be obtained on this glass specimen. A $K_{I C}$ test could most probably have been performed on the sample if the starting crack length for the $\mathrm{K}_{I C}$ test had been shorter and/or the crosshead velocity higher:

Note that the crack velocities indicated on Fig. 5 are the apparent crack velocities and that the average true crack velocities, because of the curvature and angle of the crack front. with the specimen surface, are lower by a factor. $\phi$. A method to calculate $\phi$ from the observed shape of the crack front has been proposed by Pollet and Burns (see enclosed copy). 
TABLE I: Specimen dimensions

\begin{tabular}{|c|c|c|c|c|c|c|}
\hline \multicolumn{2}{|c|}{ Specimen } & $\begin{array}{c}\mathrm{W} \\
\mathrm{mm}\end{array}$ & $\underset{\mathrm{mm}}{\mathrm{d}}$ & $c_{1}$ & $\underset{m m}{d n}$ & $\begin{array}{c}\mathrm{L} \\
\mathrm{mm}\end{array}$ \\
\hline \multirow{2}{*}{$\begin{array}{l}\text { Soda lime } \\
\text { glass }\end{array}$} & Sample A & & & & & \\
\hline & Sample B & 34.96 & 5.58 & .300 & 3.52 & $\begin{array}{l}150 \text { (original) } \\
128 \text { (equivalent) }\end{array}$ \\
\hline \multirow{2}{*}{$\begin{array}{l}9606 \\
\text { glass-ceramic }\end{array}$} & Sample A & 35.24 & 7.67 & .299 & 4.96 & 153 \\
\hline & Sample B & 35.52 & 7.66 & $.288^{\circ}$ & 5.02 & 153 \\
\hline
\end{tabular}

TABLE II: Precracking technique and precrack length

\begin{tabular}{|c|c|c|c|c|c|}
\hline \multicolumn{2}{|c|}{ Specimen } & $\begin{array}{l}\text { Clamp } \\
\text { type }\end{array}$ & $\begin{array}{l}\text { Clamp position } \\
\quad \mathrm{L}_{\mathrm{C}} \\
\therefore \mathrm{cm}\end{array}$ & $\begin{array}{c}\text { First precrack } \\
\text { length } \\
\mathrm{cm}\end{array}$ & $\begin{array}{l}\text { Precrack lengtidi } \\
\text { at instability } \\
\text { for } \mathrm{K}_{\mathrm{IC}} \\
\mathrm{cm}\end{array}$ \\
\hline \multirow{2}{*}{$\begin{array}{l}\text { soda lime } \\
\text { glass }\end{array}$} & Sample A & $A^{*}$ & $\sim 5$ & $\sim 6(?)$ & - \\
\hline & Sample. ${ }^{\dagger}$ & $B * *$ & $\sim 5$ & 2.5 & - \\
\hline \multirow{2}{*}{$\begin{array}{c}9606 \\
\text { glass-ceramic }\end{array}$} & Sample A & $A^{*}$ & $\sim 5.8$ & 9.0 & 9.0 \\
\hline & Sample B & $B * *$ & $\sim 5$ & 5.5 & $\begin{array}{r}9.3(1) \\
10.2(2) \\
\end{array}$ \\
\hline
\end{tabular}

* First clamp used: found not to be rigid enough.

$* *$.

Second clamp used: more rigid than first one.

$\dagger$

Precracked at both ends. 
8

TABLE III. K KC for pyroceram 9606

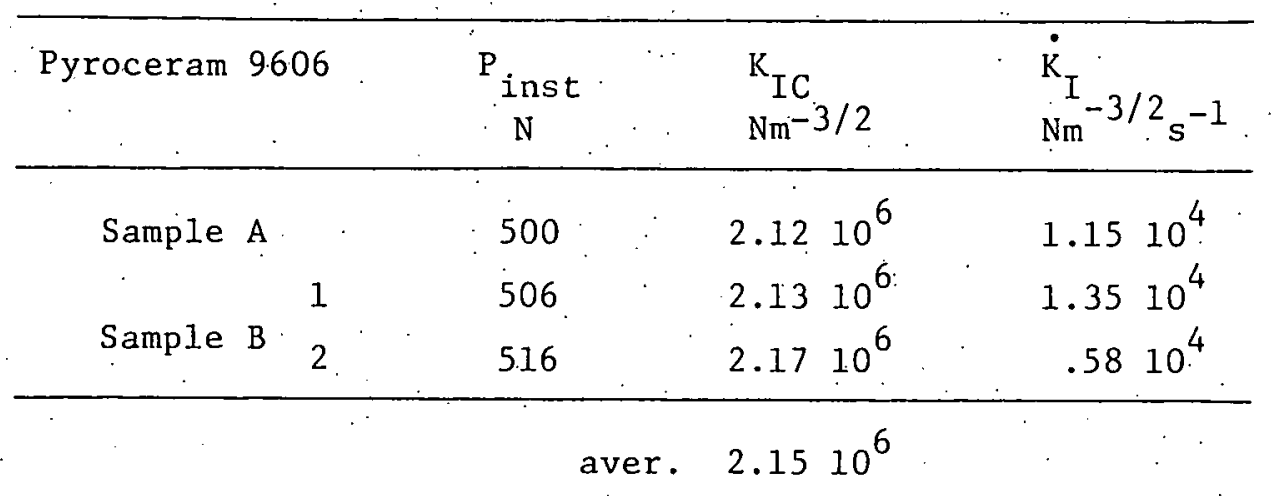




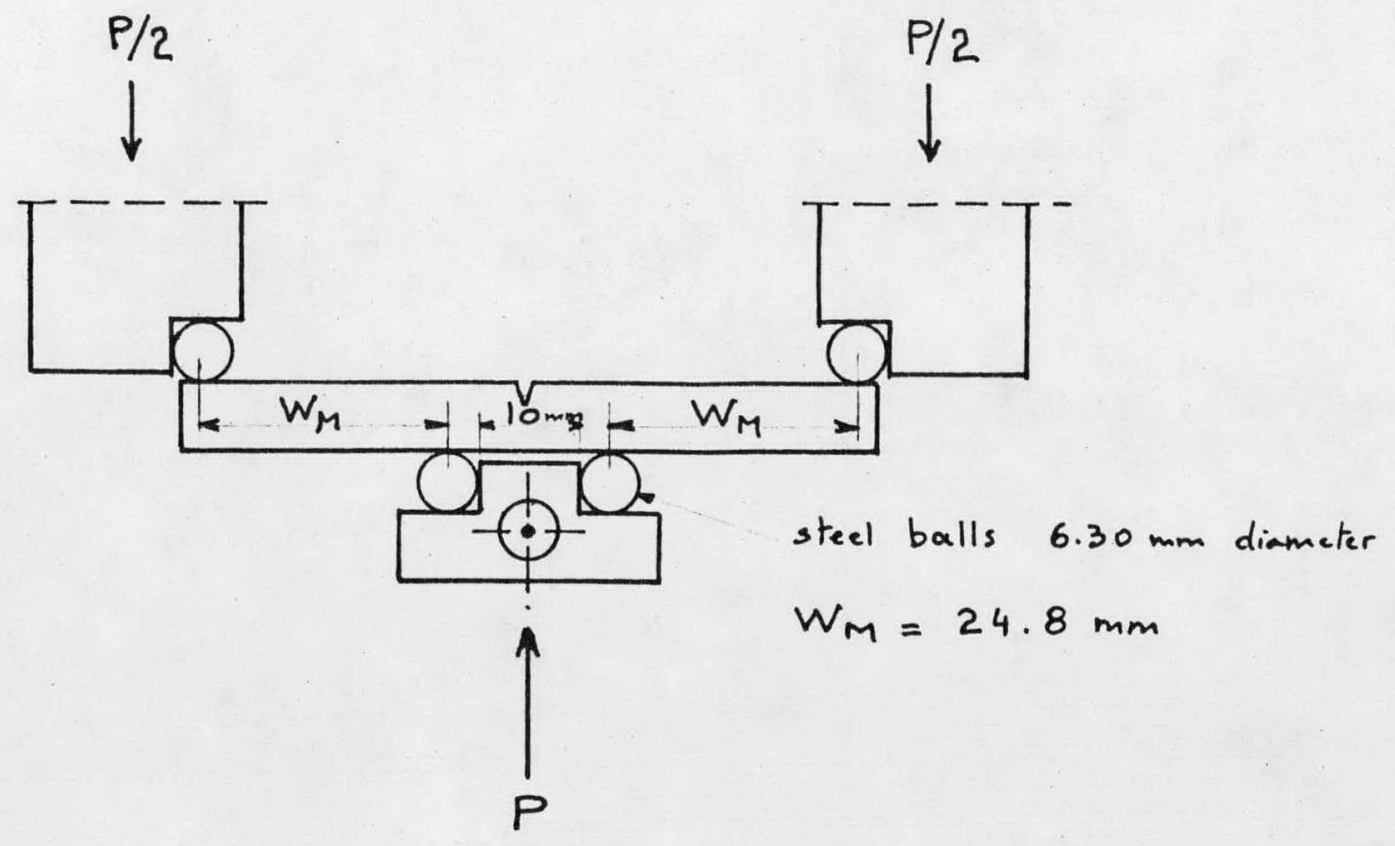

Fig. 1 : loading device for D.T.T.

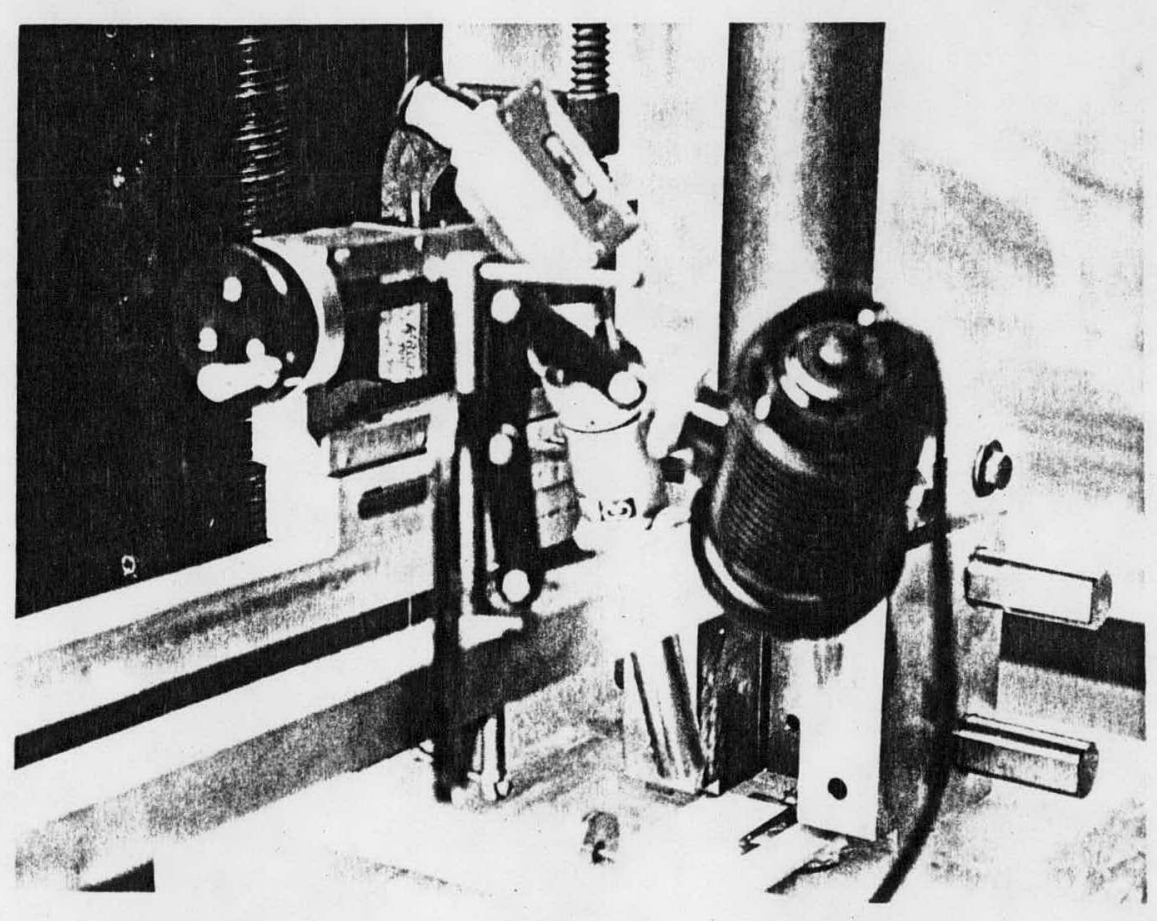

Fig. 2: Photo of loaded Specimem 


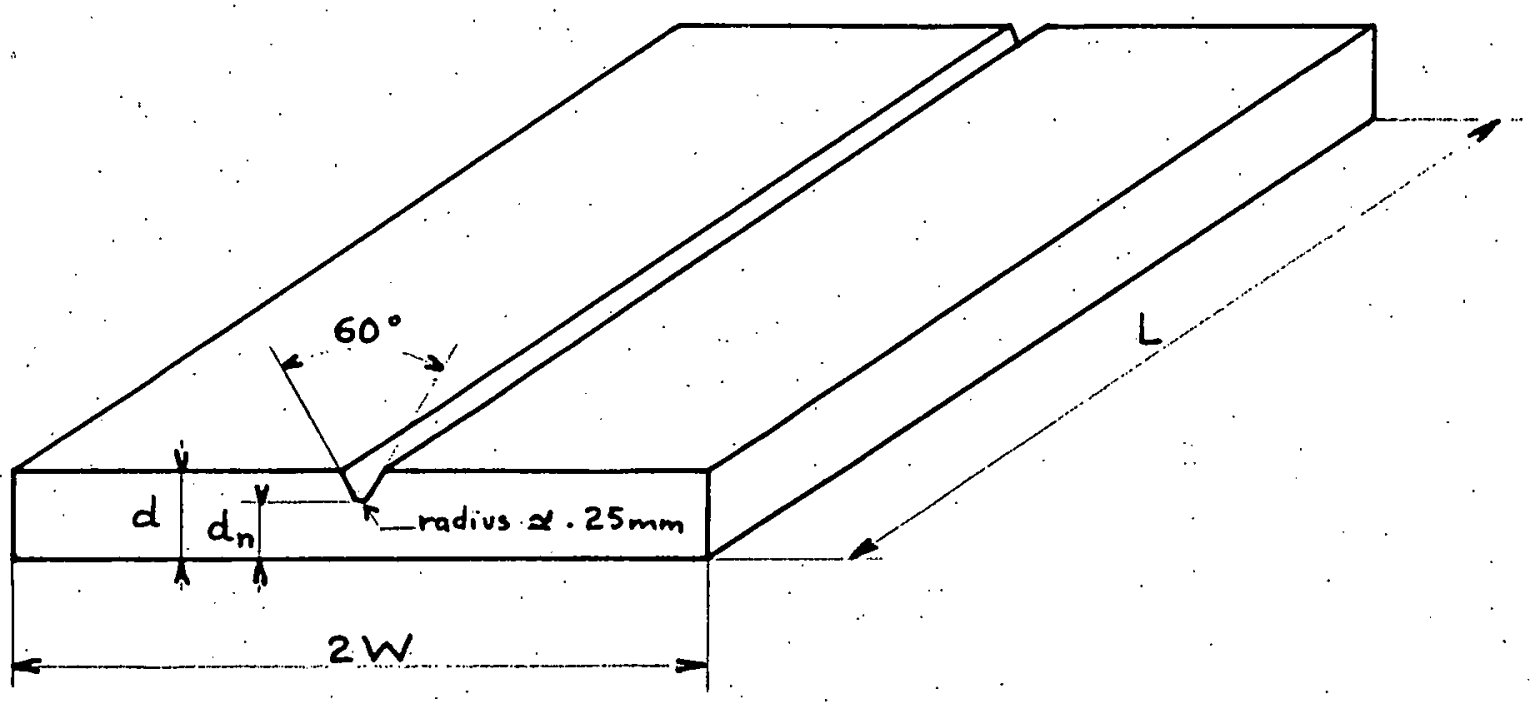

Fig. 3: Specimen for double torsion testing

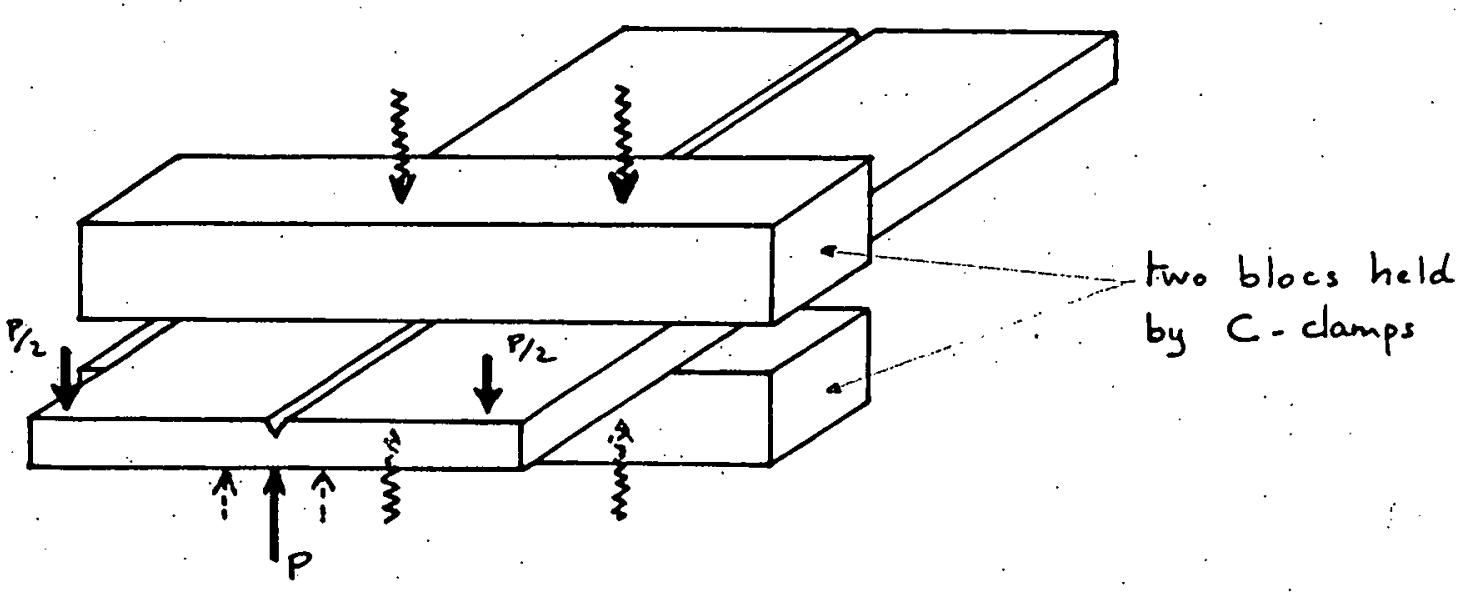

Fig. 4 : Clamp arrangement for controlling the crack length during precracking. 


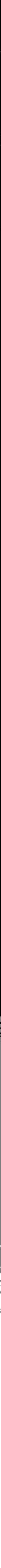




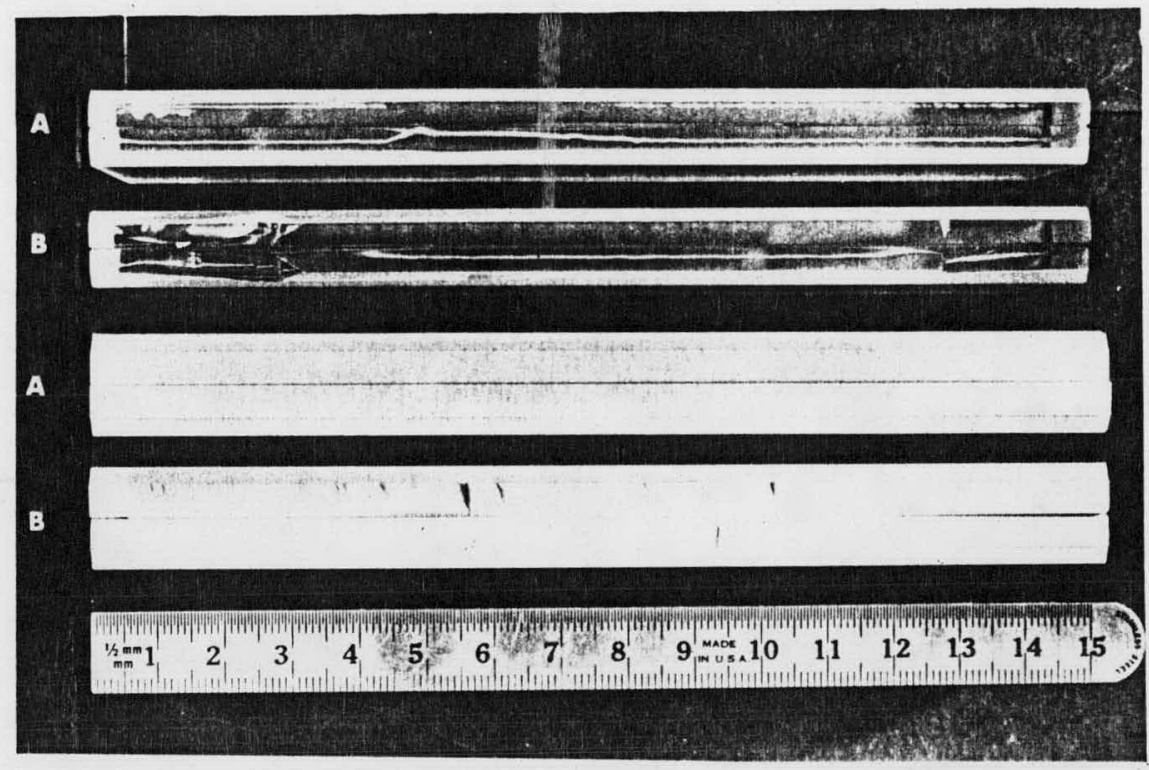
Fig. 6 :
Fracture
Surfaces 